\title{
THE ENERGY REGENERATION OF Electromagnetic ENERgy SAVINg ACTIVE SUSPENSION IN FULL VEHICLE WITH NEUROFUZZY CONTROLLER
}

\author{
Ammar A. Aldair ${ }^{1}$ and Weiji J. Wang ${ }^{2}$ \\ School of Engineering and Design, University of Sussex, Falmer, East Sussex, UK \\ 1 aa386esussex.ac.uk 2 w.j.wangdsussex.ac.uk
}

\begin{abstract}
To improve the vehicle performance such as ride comfort and road handling, the active suspension system should be used. However, the current active suspension system has a high energy consumption therefore reducing the fuel economy. In this paper the vibration excited by road unevenness is treated as a source of mechanical energy. It is being converted into electrical energy to compensate for the energy consumption by the active suspension. To achieve this task, an electromagnetic active suspension system has been introduced. The power generated from this device has been used as input power of the pump of the hydraulic actuators. Adaptive neuro-fuzzy controllers have been designed to generate a signal to control the valves of the hydraulic actuators.
\end{abstract}

\section{KEYWORDS}

Energy regeneration, Electromagnetic suspension, Full vehicle model, Neuro-fuzzy control, Nonlinear hydraulic actuators.

\section{INTRODUCTION}

The main objective of vehicle suspension systems is to isolate the vehicle body from road irregularities in order to maximize passenger riding comfort and also to secure continuous road wheel contact, ensuring the vehicle's handling quality. There are three types of suspension system: the first type is a passive suspension system which consists of conventional spring and cylindrical damper or shock absorber. This type has fixed parameters, i.e. stiffness coefficient of the spring and damping coefficient of the damper. The second type is a semi-active suspension which has a mechanical device called an "active damper" which is used in parallel with a conventional spring. The semi-active control device changes the damping of the suspension according to certain criteria. The third type is an active suspension which includes hydraulic actuators that can apply external forces to the vehicle. The actuator is secured in parallel with a spring and shock absorber.

When a vehicle is driving on a bumpy road, plus driver's acceleration and deceleration operations, there will be a shock between the sprung mass and the unsprung mass. This part of the mechanical power is normally converted into heat power by a damper and is dissipated in a natural way. If the wasted energy can be reclaimed in a proper way, the overall energy consumption demand for the vehicle can be reduced.

In recent years, research has been carried out to reduce the fuel consumption and harmful emission to protect the environment. In this direction, it has been considered that the energy used to be wasted as heat energy dissipated by the dampers can be recovered by a suitable DOI : 10.5121/ijaia.2011.2203 
energy regenerative device. In fact, there are several types of energy regenerative suspension designs already under investigation, such as hydraulic storage suspension [1], battery coil induction suspension [2], rack and pinion suspension [3], ball screw suspension [4] and linear motion suspension [5]. In recent years, researchers worldwide have made attempts on the vehicle vibration control and energy regeneration, including theoretical and experimental progresses [6-9]. Developments achieved in power electronics, permanent magnet materials, and microelectronic systems enable the possibility of actual implementation of electromagnetic actuators in order to improve the performance of vehicle suspension systems [10]. In Reference [11], the authors investigated the idea of the energy regeneration of active suspension systems in petrol-electric hybrid vehicles. A hybrid energy storage system, which consists of electrochemical batteries and super-capacitors, is proposed for this application in this reference. A new hydraulic electromagnetic energy regenerative suspension design is proposed, and a comparison is made with the other two energy regenerative suspension designs based on their structural and working principles, and made an evaluation using the fuzzy comprehensive judgement [12]. A retrofit regenerative shock absorber is designed, characterized and tested to recover the vibration energy within a compact space in an efficient way [13].

More recently, a new energy regenerative suspension prototype has been designed and developed by Xue-chun et al. at Shanghai Jiao Tong University [14]. This prototype consists of two main parts: ball screw mechanism and brushless DC motor. The ball screw part converts the vertical vibration motion into rotational motion to rotate the DC motor rotor. Depending on the direction of the current (flow through the motor's coils) with respect to dynamic tyre velocity, the DC motor may operate as an electromotor as well as a generator, i.e. when the DC motor operates as electromotor, the energy will be consumed from the battery to suppress the vehicle vibration, so that the performance of the electromagnetic suspension behaves as an active suspension system. On the other hand, when it operates as a generator, the energy will be stored in the battery and the electromagnetic suspension behaves as a passive suspension system.

In this paper, hydraulic actuators have been added to the electromagnetic suspension to produce suspension performance like an active suspension system. A neuro-fuzzy controller has been designed to generate suitable control signals. The control signals will be applied as a control input signals to govern the hydraulic actuators to generate suitable damping forces for improving the vehicle performance. In this case, the DC motor will operate as a generator only and the reclaimed vibration energy will be converted to electrical energy to operate the electrical pump in the hydraulic actuator system.

\section{Mathematical Model OF THE Hydraulic aCtUators}

Hydraulic actuators are important equipment and widely used because of their high power capability, fast and smooth response characteristics and good positioning capability [15]. The hydraulic actuators are commonly used in various industries and engineering, such as materials test machines, vehicle active suspension systems, mining machinery, flight simulators, paper making machines, ships and electromagnetic marine engineering, injection molding machines, robotics, and steel and aluminum mill equipment.

In order to understand the performance of the improved suspension system and to develop a robust controller for this system, to develop an accurate dynamic model for a hydraulic servosystem is the first step. Therefore, a description of the dynamics for the fluid subsystem, the servo-valve, the cylinder and the load are required. The electro-hydraulic system here is a cylinder controlled by the input voltage signal to the servo-valve. The cylinder is attached to sprung mass of the vehicle and connected in parallel with a passive system unit, i.e. spring and 
electromagnetic suspension. The hydraulic actuators are used to generate the forces between the vehicle's body and the axle to enhance and improve the riding and handling qualities in a modern vehicle.

Figure 1 shows the physical model of a hydraulic actuator with a nonlinear spring and an electromagnetic actuator of a quarter vehicle model.

The hydraulic actuator consists of a hydraulic cylinder, a piston, servo-valves, an electrical pump and a reservoir. $P_{s}$ and $P_{r}$ are the pressures of the hydraulic fluid supplied from and returned to the reservoir, respectively. $x_{v}$ is the spool valve displacement. When there is a difference between fluid pressure in the upper cylinder chamber and fluid pressure in the lower chamber, the piston in the hydraulic cylinder extends or compresses and a suitable damping force is generated for the suspension to improve the vehicle's dynamic performance. The dynamic equation of the hydraulic actuator is given as [16].

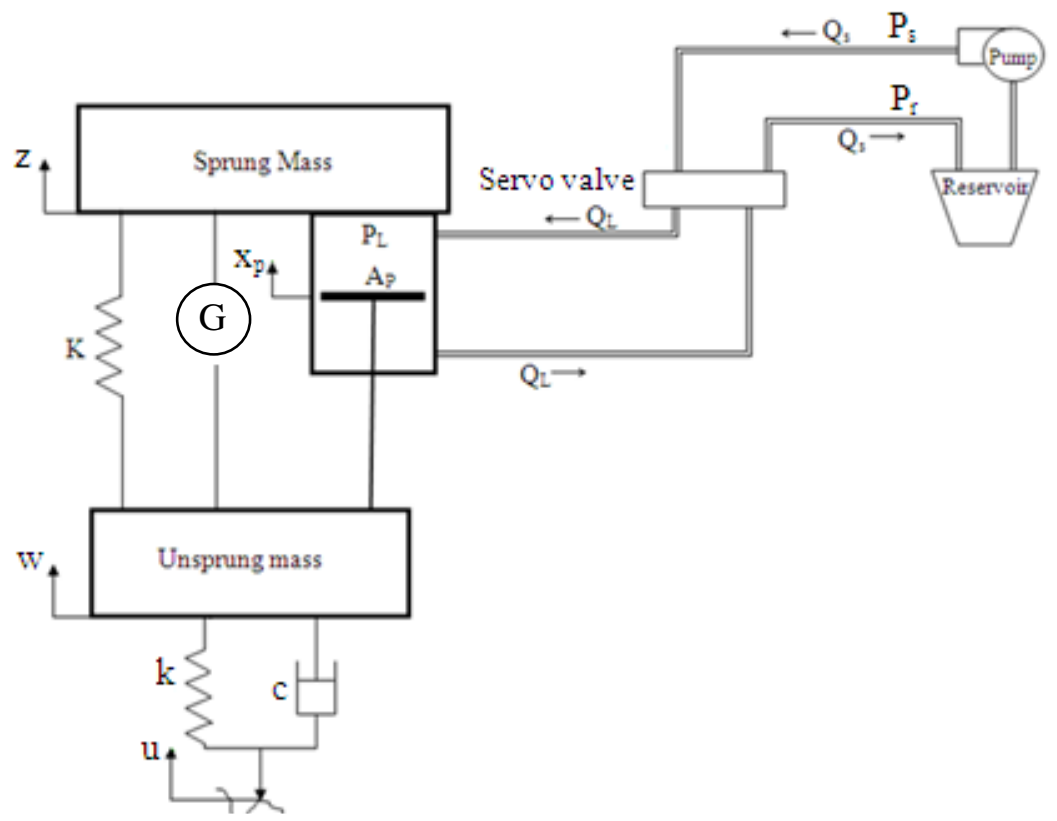

Figure 1. Active Suspension with Hydraulic Actuator

$$
\dot{P}_{L_{i}}=-\beta P_{L_{i}}-\sigma\left(A_{p} \dot{x}_{p i}-Q_{i}\right)
$$

where $\sigma=\frac{4 \beta_{e}}{V_{t}}, \beta=\sigma C_{t p}, x_{p i}=z_{i}-w_{i}$ is the relative displacement between the suspension point and wheel, $P_{L i}$ is the hydraulic pressure inside actuator, $\beta_{e}$ is the effective bulk modulus of the hydraulic system, $V_{t}$ is the total volume of fluid under compression, $C_{t p}$ is the leakage coefficient of piston and $A_{p}$ is the cross-section area of the piston. Hydraulic flow through the piston inside the ith actuator $Q_{i}$ is governed by the following equation

$$
Q_{i}=C_{d} \omega x_{v i} \sqrt{\frac{1}{\rho}\left(P_{s_{i}}-\operatorname{sgn}\left(x_{v_{i}}\right) P_{L_{i}}\right)}
$$

where $C_{d}$ is the discharge coefficient, $\omega$ the area gradient, $x_{v}$ the spool valve displacement, $\rho$ the fluid density. The spool valve displacement is controlled by an input voltage $u_{m}$. The corresponding dynamic relationship can be simplified as a first-order differential equation 


$$
\dot{x}_{v i}=\frac{1}{\tau}\left(u_{m i}-x_{v i}\right)
$$

\section{Mathematical Model of the Electromagnetic ACtUator}

The electromagnetic actuator converts the vibration energy into electrical energy through the rotation of the DC motor and stores it in the battery. The electrical energy can contribute to run the electrical pump of the hydraulic actuator. The DC motor can operate in electromotor mode or generator mode. The power of the motor $\left(P_{e}\right)$ can be represented as

$$
P_{e}=\frac{4 \pi \Phi}{P_{H}} v I
$$

where $\Phi$ is the flux linkage, $P_{H}$ the lead of the ball-screw, $v$ the relative velocity $(\dot{z}-\dot{w})$ and $I$ the electric current flow through the motor's coils. If the power demand is positive, the motor operates in electromotor mode and the current flows from the battery into the positive terminal of the motor and the battery energy is supplied and consumed. On the other hand, if the power is negative, the motor operates inversely and the current flows to the positive electrode of the battery and the motor charges the battery as a generator with reclaimed energy from vibration of the vehicle.

The torque of the DC motor $\left(T_{e}\right)$ can be written as

$$
T_{e}=C_{e} I
$$

where the equivalent torque constant $C_{T}$ can be expressed as

$$
C_{e}=2 \Phi
$$

There are two types of forces which can be generated by using an electromagnetic actuator : (i) the damping force $\left(F_{m}\right)$ coming from mechanism friction and inertia, which is given by $F_{m}=C_{m}(\dot{z}-\dot{w})$; (ii) the vertical force given by $F_{a}=F_{t} \cos \varphi$, where $\varphi$ is the thread lift angle and $F_{t}$ the tangential force given by $F_{t}=\frac{T_{e}}{r}=\frac{C_{e} I}{r}$, where $r$ is the effective radius for force conversion.

The total force generated by the electromagnetic mechanism can be written as

and

$$
F_{c}=F_{m}+F_{a}
$$

$$
F_{c}=C_{m}(\dot{z}-\dot{w})+C_{a} I
$$

in which $C_{a}=\frac{2 \Phi \cos \varphi}{r}$.

\section{Mathematical Model of The Controlled System}

A framework is being suggested in which an active suspension controller generates suitable command signals as the inputs of the hydraulic actuators to improve the vehicle performance including riding comfort and road-handling stability. The riding comfort can be measured by evaluating the displacement and acceleration of the sprung mass. The handling stability can be obtained by minimising the vertical and the rotational motions of the vehicle body, including rolling and pitching motions during sharp manoeuvres of cornering and braking.

A full vehicle physical model with active suspension is proposed by the authors and shown in Fig. 2. This model consists of five parts: the vehicle body mass $(M)$ and four unsprung masses $m_{i}$ (where $i \in[1,2,3,4]$ ). The vehicle body mass is assumed to be a rigid body and has degrees of freedom in vertical, pitch and roll directions. The vertical displacements at each suspension 
point are denoted by $z_{1}, z_{2}, z_{3}$ and $z_{4}$. The $z_{c}, \alpha$ and $\eta$ denote the displacement, pitch angle and roll angle at the centre of gravity of the vehicle, respectively. $J_{x}$ and $J_{y}$ are the moments of inertia about $\mathrm{x}$-axis and $\mathrm{y}$-axis, respectively. The cornering torque and breaking torque are denoted by $T_{x}$ and $T_{y}$, respectively. In the model, the disturbances $u_{1}, u_{2}, u_{3}$ and $u_{4}$ are caused by road roughness. The vertical displacements of unsprung masses are denoted by $w_{1}, w_{2}, w_{3}$ and $w_{4}$.

The suspension components possess nonlinear property. Therefore, each suspension will be assumed as a nonlinear device with nonlinear spring and nonlinear hydraulic actuator placed in parallel with the electromagnetic actuator. The main purpose of using the suspension control is to generate an actuating force between the vehicle body mass and unsprung masses. The $i^{\text {th }}$ nonlinear spring has a stiffness coefficient denoted by $K_{i}$. Each tyre will be simulated as a linear oscillator with stiffness and damping coefficient denoted by $k_{i}$ and $c_{i}$, respectively.

The motion of the vehicle body mass is governed by the following equations:

\section{Vertical motion}

Using Newton's Second Law of Motion

$$
M \ddot{z}_{c}=-\sum_{i=1}^{4} F_{K i}-\sum_{i=1}^{4} F_{C i}+\sum_{i=1}^{4} F_{P i}
$$

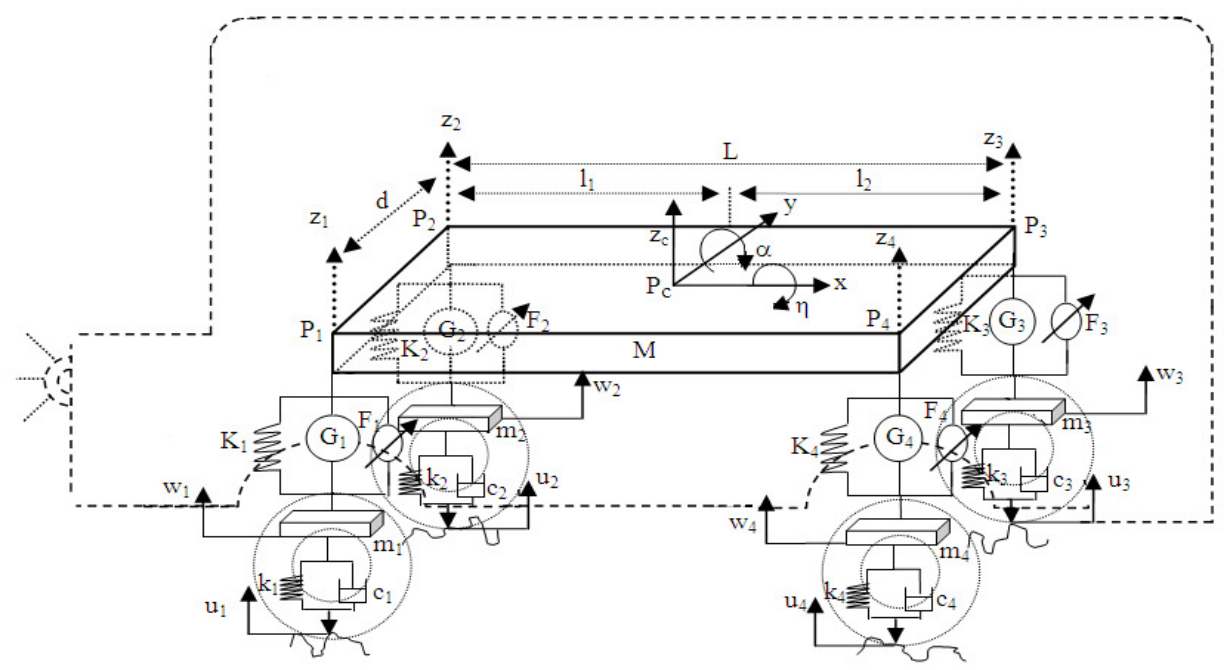

Figure 2. Full Vehicle Nonlinear Active Suspension System

where $F_{K i}$ is the $i^{\text {th }}$ nonlinear suspension spring force which can be written as [17]

$$
F_{K i}=K_{i}\left(z_{i}-w_{i}\right)+\xi K_{i}\left(z_{i}-w_{i}\right)^{3}
$$

where the $i^{t h}$ electromagnetic force $F_{C i}$ is given by Eq. (8). $F_{P i}=F_{A i}-F_{f i}$, where $F_{A i}$ is the nonlinear hydraulic force provided by the $i^{\text {th }}$ actuator $\left(F_{A i}=A_{p} P_{L i}\right)$ and $F_{f i}$ the nonlinear frictional force due to rubbing of piston seals against the cylinders wall inside the $i^{\text {th }}$ actuator. Frictional force is modeled by a smooth approximation of Signum function 


$$
F_{f i}=\left\{\begin{array}{l}
\kappa \operatorname{sgn}\left(\dot{z}_{i}-\dot{w}_{i}\right) \text { if }\left|\dot{z}_{i}-\dot{w}_{i}\right|>0.01 \\
\kappa \sin \left(\frac{\dot{z}_{i}-\dot{w}_{i}}{0.01} \frac{\pi}{2}\right) \text { if }\left|\dot{z}_{i}-\dot{w}_{i}\right|<0.01
\end{array}\right.
$$

\section{Pitching motion}

Using Newton's Law for the pitching motion

$$
J_{x} \ddot{\alpha}=\left(F_{K 1}-F_{K 2}-F_{K 3}+F_{K 4}\right) \frac{b}{2}+\left(F_{C 1}-F_{C 2}-F_{C 3}+F_{C 4}\right) \frac{b}{2}+\left(F_{P 4}-F_{P 1}+F_{P_{3}}-F_{P 2}\right) \frac{b}{2}+T_{x}
$$

where $b$ is the distance between the front wheels.

\section{Rolling motion}

Using Newton's Law again for the rolling motion

$$
J_{y} \ddot{\eta}=\left(F_{K 3}+F_{K 4}\right) l_{2}-\left(F_{K 1}+F_{K 2}\right) l_{1}+\left(F_{C 3}+F_{C 4}\right) l_{2}-\left(F_{C 1}+F_{C 2}\right) l_{1}+\left(F_{P 1}+F_{P 2}\right) l_{1}+\left(F_{P 3}+F_{P 4}\right) l_{2}+T_{y}
$$

where $l_{l}$ is the distance between the centre of the front wheel axle and centre of gravity of the vehicle. $l_{2}$ is the distance between the centre of gravity of the vehicle and the centre of rare wheel axle. The motion of the $i^{\text {th }}$ unsprung mass is governed by the following equation

$$
m_{i} \ddot{w}_{i}=-k_{i}\left(w_{i}-u_{i}\right)-c_{i}\left(\dot{w}_{i}-\dot{u}_{i}\right)+F_{K i}+F_{C i}-F_{P_{i}}
$$

\section{Design of Neuro-Fuzzy ConTroller}

A neuro-fuzzy model has been introduced to combine the features of a neural network and fuzzy logic models. A large class of neuro-fuzzy approaches utilizes the neural network learning algorithms to determine parameters of the fuzzy logic component. The combined neuro-fuzzy system is proving more efficient and more powerful than either the single neural network or the fuzzy logic system, which has been widely used in control systems, pattern recognition, medicine, expert system, etc. Fig. 3 depicts the controlled vehicle system with a neuro-fuzzy controller as a key component. The structure of the NF controller in this figure is described in Reference [18]. To find the optimal values of the NF parameters, such as premise and consequent parameters, for driving the plant to meet all control objectives, FOPID subcontroller should be designed (see details for the full design of FOPID controller described in Reference [19]). The input and output data which will be obtained from the FOPID controller design are made use of in training the NF controller.

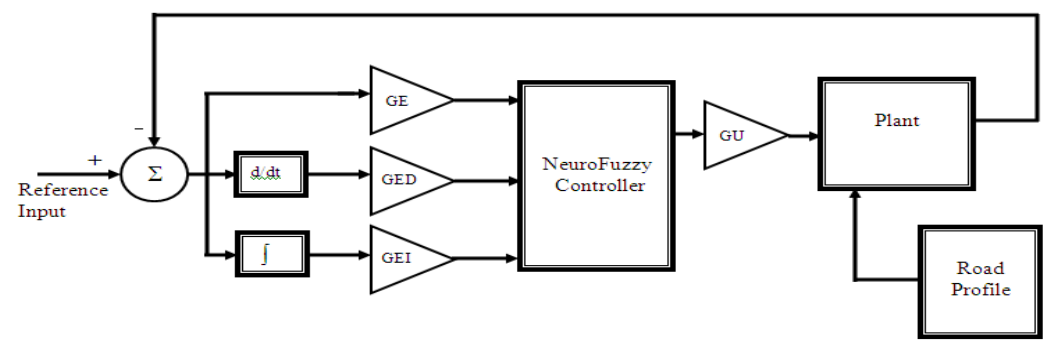

Figure 3. Neuro-fuzzy controller for a full vehicle model 
After the optimal parameters of the FOPID controller are obtained, the input and output data of the FOPID controller should be used to train the parameters of the NF controller using the Hybrid Learning Algorithm. Fig. 4 depicts the training phase of the NF controller.

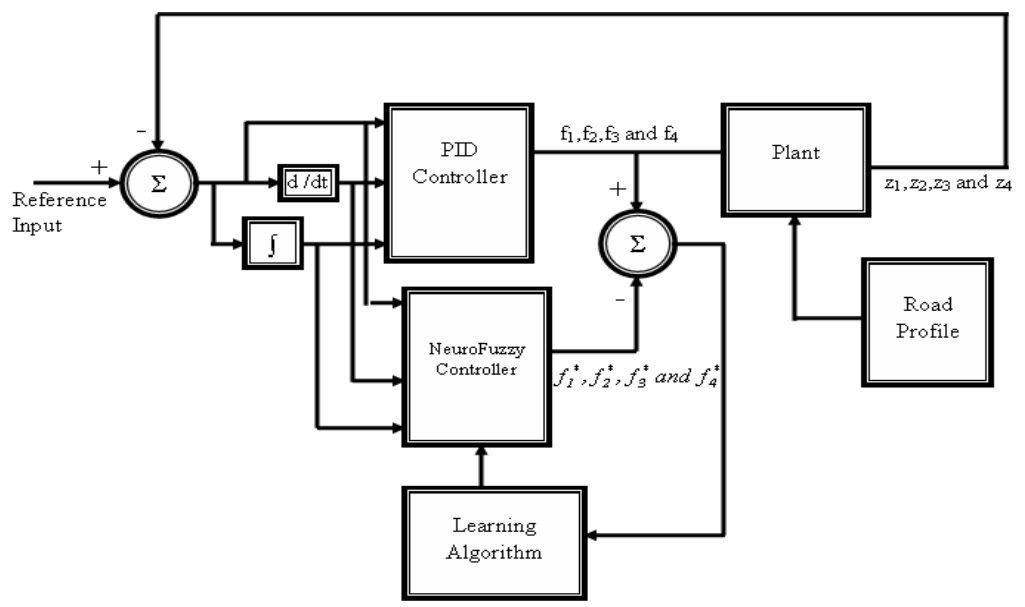

Figure 4. Training phase of the NF controller

The bold line means multiple input or output signals. After the optimal values of NF are obtained the NF controller design should be improved by adjusting the scaling gains, i.e. GE, GED, GEI and GU, as shown in Fig. 3. To select the optimal values of the scaling gains, a fourdimensional Golden Section Search (4-D GSS) method is introduced to reduce the trial time (For more detail about 4-D GSS method, see Reference [20]).

\section{Simulation AND Results}

The damping coefficient and damped natural frequency for the full vehicle depend on the vehicle structural parameters $M, K$, and $C$. Table 1 shows the vehicle suspension parameters. The input road profile is selected as a white noise random signal. To design the NF controller, the optimal parameters of the FOPID controller should be obtained first, using the EA. In the author's work, the input and output data obtained from the FOPID controller have been used to design the NF controller. The Hybrid Learning Algorithm has been used to modify the NF parameters (i.e. the premise and consequent parameters) to track the input and output data obtained from the FOPID controller. Four NF controllers have been designed, one for each suspension. To improve the performance of the NF controller, the scaling gains should be adjusted. The 4-D GSS method has been used to adjust the scaling gains (GE, GED, GEI and GU). As a result, the optimized values of scaling gains are 26, 22, 10 and 1.5, respectively.

All vehicle body variables, including vertical displacement at the centre of gravity $\mathrm{z}_{\mathrm{c}}$, vertical displacement at point $3 z_{3}$, pitch angle: $\alpha$ and roll angle $\eta$, depend on the vertical displacements at points $P_{1}, P_{2}$ and $P_{4}\left(\mathrm{z}_{1}, \mathrm{z}_{2}\right.$ and $\mathrm{z}_{4}$, respectively). The suspension deflection $\left(z_{i}-w_{i}\right)$ and body acceleration $\left(\ddot{z}_{c}\right)$ are used to evaluate the road handling and riding comfort of the passengers, respectively. By supplying the control signal, it is expected that just the vertical displacements of sprung mass $\left(z_{i}\right)$ and body acceleration $\left(\ddot{z}_{c}\right)$ will be targeted to reduce while the vertical displacements of unsprung masses $\left(w_{i}\right)$ are not concerned. Therefore, when $z_{i}$ decreases, the road-handling performance will be improved while body acceleration decreases, the riding comfort is improved. In this paper, just the responses of the vertical displacements at $P_{1}, P_{2}$ and $P_{4}$ and the body acceleration have been shown for comparison. In Figures 5,6 and 7 the 
responses of vertical displacements at $P_{1}, P_{2}$ and $P_{4}$ are compared, respectively for the full vehicle nonlinear active suspension system without controller (passive system) and with NeuroFuzzy controller. Figure 8 shows the response of the acceleration at the vehicle's centre of gravity. From these figures, it can be seen that the proposed controller (NF controller) is powerful and efficient.

Table 1.Vehicle suspension parameters

\begin{tabular}{|c|c|c|c|}
\hline Notation & Description & Values & Units \\
\hline$K_{1}, K_{2}$ & $\begin{array}{l}\text { Front-left and Front-right } \\
\text { suspension stiffness, } \\
\text { respectively. }\end{array}$ & 19960 & $\mathrm{~N} / \mathrm{m}$ \\
\hline$K_{3}, K_{4}$ & $\begin{array}{l}\text { Rear-right and rear-left } \\
\text { suspension stiffness, } \\
\text { respectively. }\end{array}$ & 17500 & $\mathrm{~N} / \mathrm{m}$ \\
\hline$k_{1}-k_{4}$ & $\begin{array}{l}\text { Front-left, front-right, rear- } \\
\text { right and rear-left tyre } \\
\text { stiffness respectively. }\end{array}$ & 175500 & $\mathrm{~N} / \mathrm{m}$ \\
\hline$C_{m}$ & Damping force constant & 200 & N.sec/m \\
\hline$C_{a}$ & Vertical force constant & 17.6 & V.sec/m \\
\hline$c_{1}-c_{4}$ & $\begin{array}{l}\text { Front-left, Front-right, rear- } \\
\text { right and rear-left tyre } \\
\text { damping, respectively. }\end{array}$ & 14.6 & N.sec $/ \mathrm{m}$ \\
\hline$M$ & Sprung mass. & 1460 & $\mathrm{~kg}$ \\
\hline$m_{l}, m_{2}$ & $\begin{array}{l}\text { Front-left, Front-right tyre } \\
\text { mass, respectively. }\end{array}$ & 40 & $\mathrm{~kg}$ \\
\hline$m_{3}, m_{4}$ & $\begin{array}{c}\text { Rear-right and rear-left tyre } \\
\text { mass, respectively. }\end{array}$ & 35.5 & $\mathrm{~kg}$ \\
\hline$J_{x}$ & $\begin{array}{l}\text { Moment of inertia in } \mathrm{x}- \\
\text { direction. }\end{array}$ & 460 & kg.m ${ }^{2}$ \\
\hline$J_{y}$ & $\begin{array}{l}\text { Moment of inertia in } \mathrm{y}- \\
\text { direction. }\end{array}$ & 2460 & $\mathrm{~kg} \cdot \mathrm{m}^{2}$ \\
\hline$l_{l}$ & $\begin{array}{l}\text { Distance between the centre } \\
\text { of gravity of vehicle body } \\
\text { and front axle. }\end{array}$ & 1.011 & $\mathrm{~m}$ \\
\hline$l_{2}$ & $\begin{array}{l}\text { Distance between the centre } \\
\text { of gravity of vehicle body } \\
\text { and rear axle. }\end{array}$ & 1.803 & $\mathrm{~m}$ \\
\hline$b$ & Width of vehicle body & 1.51 & $\mathrm{~m}$ \\
\hline$\zeta$ & Empirical parameter & 0.1 & - \\
\hline$\alpha, \beta, \gamma$ & Actuator parameters & $\begin{array}{l}4.515 * 10^{13} \\
, 1 \\
1.545^{*} 10^{9}\end{array}$ & - \\
\hline$A_{P}$ & Cross-section area of piston & $3.35 * 10^{-4}$ & $\mathrm{~m}^{2}$ \\
\hline$P_{S}$ & Supply pressure & 10342500 & $\mathrm{~Pa}$ \\
\hline$\tau$ & Time constant & $1 / 30$ & sec \\
\hline$\overline{C_{d}}$ & Discharge coefficient & 0.7 & - \\
\hline$\rho$ & Fluid density & 970 & $\mathrm{~kg} / \mathrm{m}^{3}$ \\
\hline$\omega$ & Area gradient & $1.436 \mathrm{e}-2$ & $\mathrm{~m}^{2}$ \\
\hline
\end{tabular}


International Journal of Artificial Intelligence \& Applications (IJAIA), Vol.2, No.2, April 2011

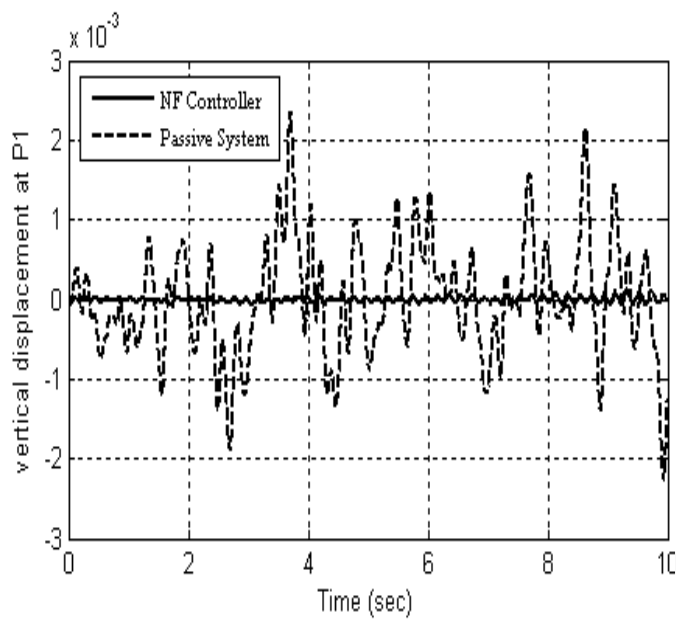

Figure 5. Time response of a vertical displacement at $\mathrm{P} 1$

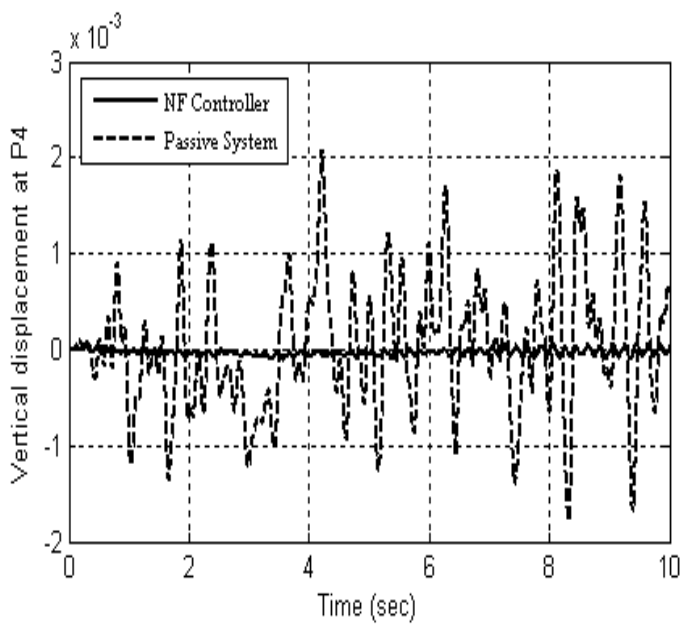

Figure 7. Time response of a vertical displacement at $\mathrm{P} 4$

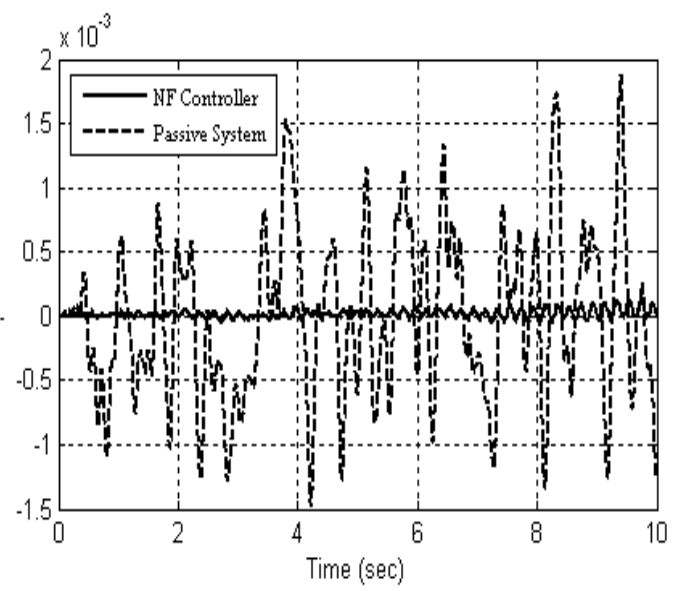

Figure 6. Time response of a vertical disnlacement at $\mathrm{P} 2$

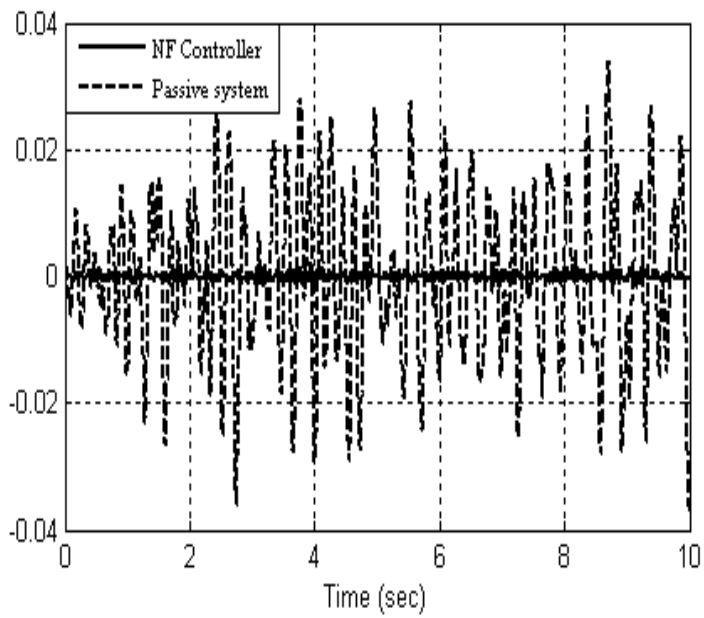

Figure 8. Time response of a vertical acceleration at

The power generated from DC motors of each electromagnetic active suspension device is shown in Figures 9, 10, 11 and 12. These figures have shown that the DC motors operate as a generator only (when the power generated is negative). The energy will contribute to drive the pumps of the hydraulic actuators to generate damping forces as part of the effort of improving the vehicle performance. 


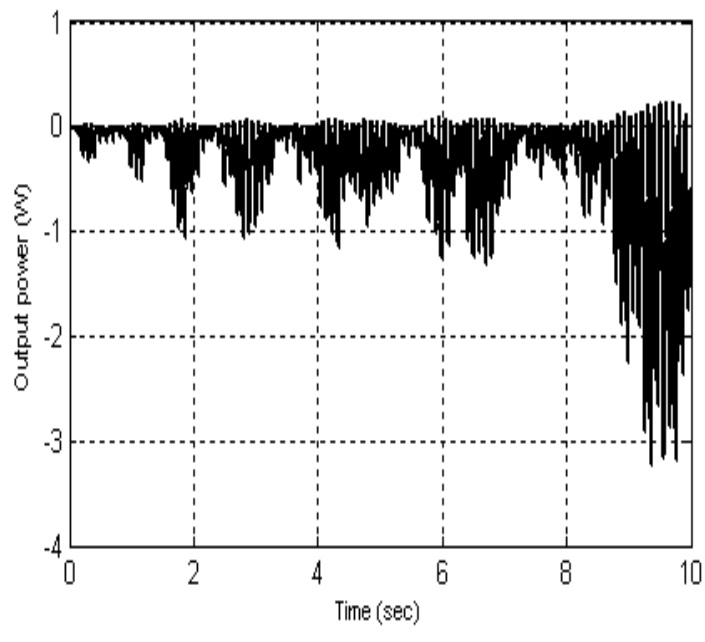

Figure 9. Output power from front-right suspension

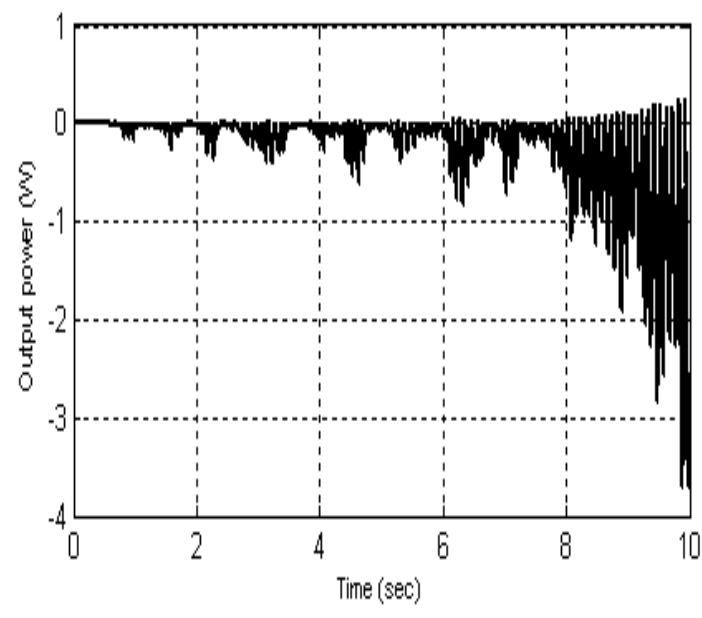

Figure 11. Output power from rear-right suspension

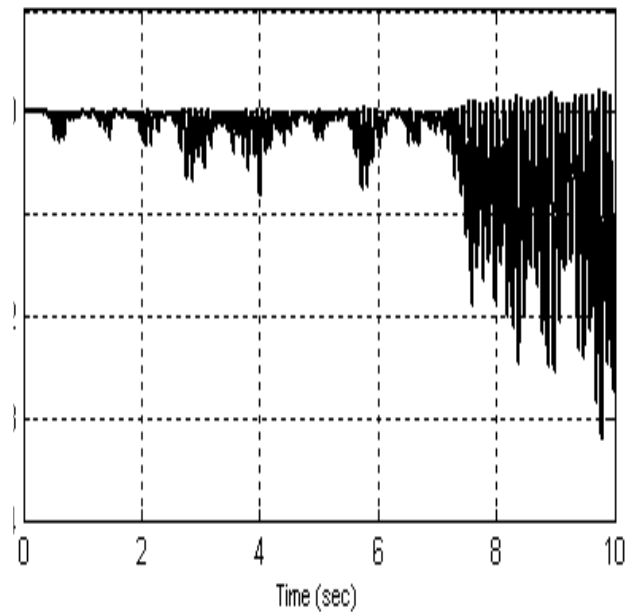

Figure 10. Output power from front-left suspension

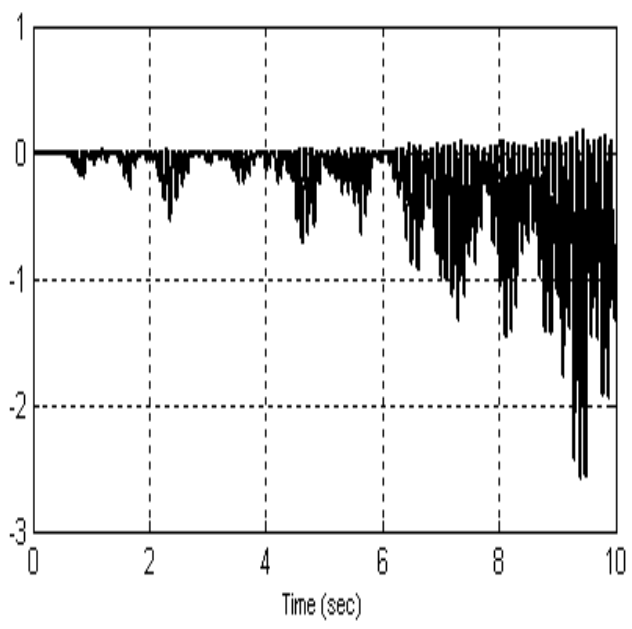

Figure 12. Output power from rear-Left suspension

\section{CONCLUSION}

An optimized neuro-fuzzy controller has been designed as the key part of a proposed full vehicle model with nonlinear active suspension systems. To reduce the energy consumption resulting for driving the actuators in active suspension, the electromagnetic device has been introduced, which is capable of converting most of the vehicle's vibration energy into electrical energy through the rotation of the device, and store them in the battery. By applying the electromagnetic devices to two example cases, optimistic results have been found: the overall power consumption of the active suspension system has been reduced and the previous heat energy dissipated to the viscous fluid of the damper has been converted to useful electrical energy to run the electrical pump in the hydraulic actuator device. When the electromagnetic 
International Journal of Artificial Intelligence \& Applications (IJAIA), Vol.2, No.2, April 2011

device does not act as an electromotor but a generator, the power generated and stored in the battery will be used to run the pump of the hydraulic actuators to generate appropriate damping forces to improve the riding comfort and road handling. The results show that the electromagnetic device does act as a power generator. i.e., all the vibration energy excited by the rough road surface has been converted to useful electrical energy.

As a result, two targets have been met by using hydraulic actuators with electromagnetic suspension systems: increasing fuel economy and improving the vehicle performance.

\section{REFERENCES}

[1] Shian, C., H. Ren, and Senlin, L. New Reclaiming Energy Suspension and its Working Principle Chinese Journal of Mechanical Engineering, 2007. 13(11): pp. 177-182.

[2] Ren, H., C. Shian, and L. Senlin, A Permanent Magnetic Energy Regenerative Suspension. ZL 200520072480.9, 2005.

[3] Shian, C., H. Ren, and Senlin, L. Operation Theory and Structure Evaluation of Reclaiming Energy Suspension. Transactions of the Chinese Society for Agricultural Machinery, 2006. 37(5): pp. 5-9.

[4] Yong-chao, Z., et al., Isolation and Energy Regenerative Performance Experimental Verification of Automotive Electrical Suspension. Journal of Shanghai Jiaotong University, 2008. 42(6): pp. 874-877.

[5] Zhengquan, W. and C. Yu, Brief Introduction to Structure and Principle of Electromagnetic Shock Absorber. Motor Technology, 2007. 8: pp. 56-59.

[6] Karnopp, D., Power requirements for traversing uneven roadways. Vehicle System Dynamics, 1978. 7: pp. 135-152.

[7] Velinsky, S. and R. White, Vehicle Energy Dissipation due to Road Roughness. Vehicle System Dynamics, 1980. 9: p. 359-384.

[8] Karnopp, D., Permanent Magent Linear Motors used as Variable Mechanical Dampers for Vehicle Suspensions. Vehicle System Dynamics, 1989. 18: pp. 187-200.

[9] Suda, Y. and T. Shiiba, New Hybrid Suspension System with Active Control and Energy Regeneration. Vehicle System Dynamics, 1996. 25: pp. 641-654.

[10] Martins, I., et al., Permanent-Magnets Linear Actuators Applicability in Automobile Active Suspensions. IEEE Transaction on Vehicular Technology,, 2006. 55(1): pp. 8694.

[11] Montazeri, M. and M. Soleymani, Investigation of the Energy Regeneration of Active Suspension Systemin Hybrid Electric Vehicles. IEEE Transaction on Industral Electronics, 2010. 57(3): pp. 918-925.

[12] Xu, L., X. Guo, and J. Liu, Evaluation of Energy-regenerative Suspension Structure Based on Fuzzy Comprehensive Judgment. Advanced Materiral Research, 2010. 139141: pp. 2636-2642.

[13] Zuo, L., et al., Design and Characterization of an Electromagnetic Energy Harvester for Vehicle Suspensions. Smart Mater. Structure, 2010. 19: pp. 1-10.

[14] Xue-chun, Z., U. Fan, and Z. Yong-chao, A Novel Energy Regenerative Active Suspension for Vehicles. J. Shanghai Tiaotong University, 2008. 13(2): pp. 184-188.

[15] Zulfatman and Rahmat M., Application of Self-tuning Fuzzy PID Controller on Industral Hydraulic Actoutor Using System Identification Approach. International Journal on Smart Sensing and Intelligent System, 2009. 2(2): pp. 246-261.

[16] H, M., Hydrulic Control Systems 1967, New York: John Wiley and Sons, Inc. 
International Journal of Artificial Intelligence \& Applications (IJAIA), Vol.2, No.2, April 2011

[17] Ando, Y. and M. Suzuki, Control of Active Suspension System Using the Singular Perturbation Method Control. Engineering Practice, 1996. 4(3): pp. 287-293.

[18] Aldair, A. and W. Wang, FPGA Based Adaptive Neuro-Fuzzy Inference Controller for Full Vehicle Nonlinear Avtive Suspension System. International Journal of Artificial Intelligence and Applications (IJAIA), 2010. 1(4): pp. 1-13.

[19] Aldair, A. and W. Wang, Design of Fractional order Controller Based on Evolutionary Algorithm for a Full Vehical Nonlinear Active Suspension System. International Journal of Control and Automation (IJCA), 2010. 3(4): pp. 33-46.

[20] Chang, Y., N-Dimension Golden Section Search: Its Variants and Limitations. 2nd International Conference on Biomedical Engineering and Informatics, BMEI'09, 2009: pp. 1-6.
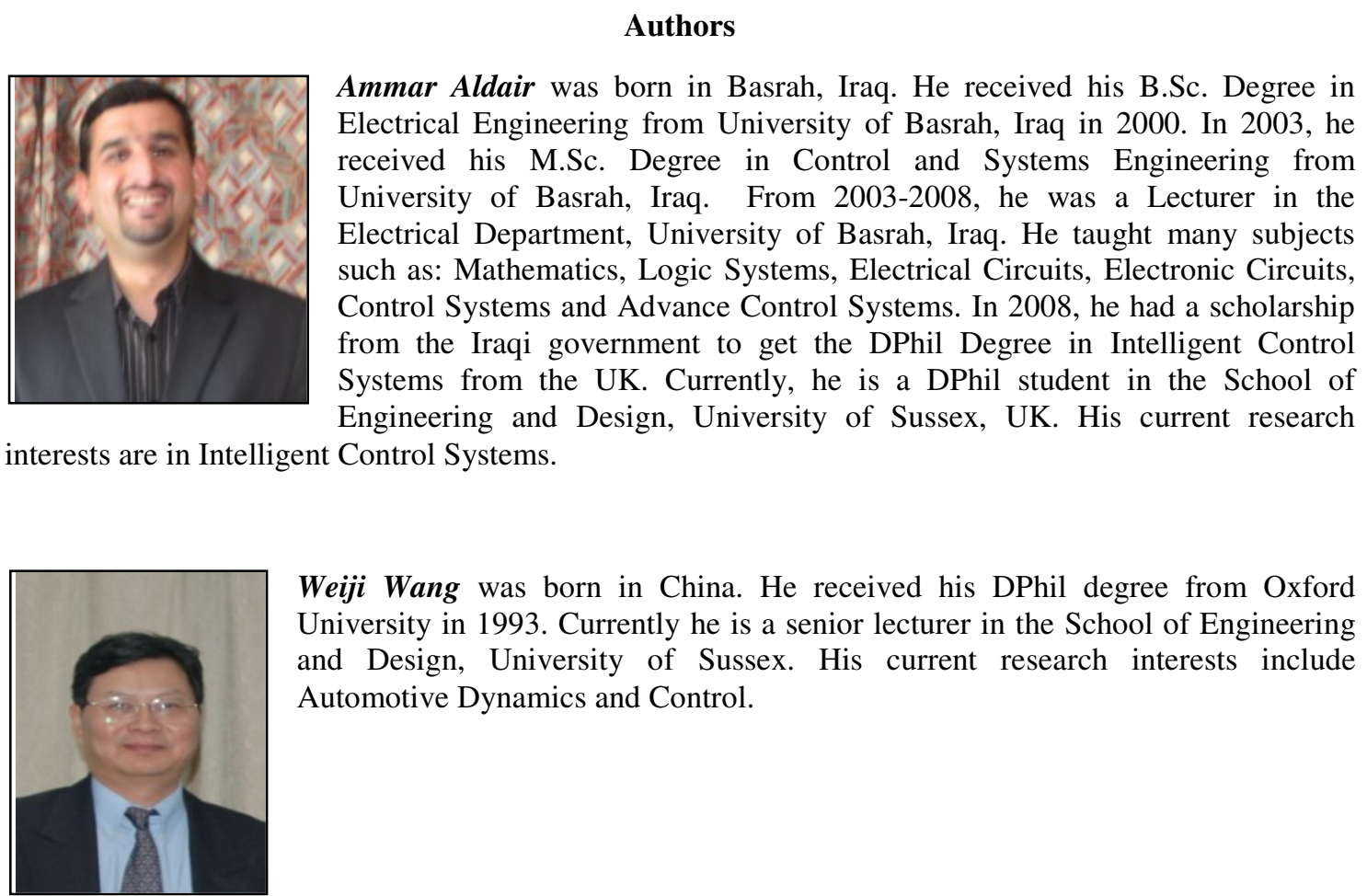

Weiji Wang was born in China. He received his DPhil degree from Oxford University in 1993. Currently he is a senior lecturer in the School of Engineering and Design, University of Sussex. His current research interests include Automotive Dynamics and Control. 